Article

\title{
Will We Have a Cohort of Healthcare Workers Full Vaccinated against Measles, Mumps, and Rubella?
}

\author{
Andrea Trevisan * $\mathbb{D}$, Chiara Bertoncello, Elisa Artuso, Clara Frasson, Laura Lago, \\ Davide De Nuzzo ${ }^{\mathbb{D}}$, Annamaria Nicolli and Stefano Maso \\ Department of Cardiac Thoracic Vascular Sciences and Public Health, University of Padova, 35128 Padova, Italy; \\ chiara.bertoncello@unipd.it (C.B.); elisa.artuso@unipd.it (E.A.); clara.frasson@unipd.it (C.F.); \\ laura.lago@unipd.it (L.L.); ddenuzzo@gmail.com (D.D.N.); annamaria.nicolli@unipd.it (A.N.); \\ stefano.maso@unipd.it (S.M.) \\ * Correspondence: andrea.trevisan@unipd.it
}

Received: 10 February 2020; Accepted: 25 February 2020; Published: 27 February 2020

check for updates

\begin{abstract}
Healthcare workers are a population exposed to several infectious diseases, and an immunization programme is essential for the maintenance of good vaccination coverage to protect workers and patients. A population of 10,653 students attending degree courses at Padua Medical School (medicine and surgery, dentistry and health professions) was screened for vaccination coverage and antibody titres against rubella, mumps, and measles. The students were subdivided into five age classes according to their date of birth: those born before 1980, between 1980 and 1985, between 1986 and 1990, between 1991 and 1995, and after 1995. Vaccination coverage was very low in students born before 1980, but the rate of positive antibody titre was high due to infection in infancy. Increasing date of birth showed increased vaccination coverage. In contrast, immune coverage was high for rubella (more than 90\%) but not for mumps and measles (approximately 80\%). An "anomaly" was observed for mumps and measles in the cohort born between 1991 and 1995, probably due to the trivalent vaccine formulation. Students born after 1990 showed vaccination coverage that exceeded $90 \%$. It is therefore very likely that we will have a future generation of healthcare workers with optimal vaccination coverage.
\end{abstract}

Keywords: rubella; mumps; measles; healthcare workers; immune coverage; vaccination coverage

\section{Introduction}

Healthcare workers (HCWs) constitute a population potentially exposed to transmittable infectious disease because of their work. Owing to this potential exposure, the Italian "National Vaccination Prevention Plan" 2017-2019 strongly suggests that healthcare workers (HCWs) be vaccinated against seven transmittable diseases. Furthermore, in 2017, the so-called "Pisa card" was drawn up by several scientific societies during the national conference "Medice cura te ipsum" (Pisa 27-28 March 2017). However, currently, there are no mandatory vaccinations for HCWs in Italy.

Among the seven suggested vaccines are those against rubella $(\mathrm{Ru})$, mumps $(\mathrm{Mu})$ and measles (Me), usually combined as a trivalent vaccine (MMR), introduced in Italy in 1999 (circular n. 12) and approved by the National Plan for the Eradication of Measles and Congenital Rubella (Ministry Decree November 29, 2001), according to the objectives of the World Health Organization (WHO, Global Measles and Rubella Strategic Plan 2012-2020).

The MMR vaccination schedule provides a first dose in the second year of life and a second dose at 5-6 (recommended) or 11-12 years of age. As a consequence, the incidence of Me dramatically decreased over time. In contrast, probably due to, on the one hand, a "loss of confidence" with the disease and, on the other hand, the growth of the no-vax movements, the trend in vaccine coverage (in 
particular for MMR) in Italy decreased over time [1]. This decrease was most likely the main cause of the Me outbreak in 2017. As a consequence, since June 7, 2017, MMR is mandatory in Italy (Law Decree n. 73) for new-borns and for adolescents until 16 years of age.

A two-dose schedule is universally recommended for Me [2], with an effectiveness of more than 95\% after the first dose and an increase to $99 \%$ after the second dose. Immunity persists for a long time [3]. On the other hand, as ascertained previously, Ru protection generally appears to be high, whereas $\mathrm{Mu}$ and Me protection does not [4].

The objectives of the present research, performed in a large cohort of students belonging to the Medical School of Padua University susceptible to contract and/or to transmit the infection owing to their future job, were analysed for the MMR vaccine and immune coverage with the aim to evaluate whether, in the near future, it will be possible to have a new generation of HCWs fully vaccinated (and immunized) against $\mathrm{Me}, \mathrm{Mu}$, and $\mathrm{Ru}$. Answers were also sought to other questions that arose during the analysis of the results.

\section{Materials and Methods}

\subsection{Population}

According to Italian law on occupational safety and health (legislative decree 81/08), students attending to the degree courses of the Medical School of Padua University (medicine and surgery, dentistry, and health professions) are subjected to health surveillance in the second (dentistry and medicine and surgery until 2017) or the first (medicine and surgery from 2018 and health professions) year of coursework. From 2004 until 2019, students were screened for antibodies against transmissible but preventable diseases, including $\mathrm{Me}, \mathrm{Mu}$, and $\mathrm{Ru}$. The enrolment conditions were as follows: the students were born in Italy (thus, they had the same vaccination schedules); and their certificate of vaccination, released from the Public Health Office, stating whether the student had been vaccinated against $\mathrm{Ru}, \mathrm{Mu}, \mathrm{Me}$ or MMR, was available. In total, 10,653 students were enrolled (3714 males and 6939 females, male/female ratio 0.54).

The enrolled students included 4705 students (44.2\%) from medicine and surgery, 345 students $(3.2 \%)$ from dentistry, and 5603 students $(52.6 \%)$ from health professions. They were mostly from Northern Italy $(93.8 \%)$, and among these, $86.1 \%$ were from the Veneto region $(86.1 \%)$, predominantly from the province of Padua (33.9\%).

The students were further subdivided according to the year of birth, from 1980 to 2000, and were categorized into classes as follows: those born between 1980 and 1985, 1986 and 1990, 1991 and 1995, and after 1995. Students born before 1980 were included in one class.

This was an observational study in which we analysed data from a mandatory health surveillance activity on workers exposed to biological risks regulated by the Italian law D. Lgs. 81/2008; consequently, evaluation by an ethics committee was not necessary. However, students signed an informed consent form on the processing of personal and sensitive data, in which they also expressed consent to the possibility that the data collected would be processed anonymously for epidemiological investigations and/or for scientific research purposes.

\subsection{Measurement of MMR Antibodies}

The measurement of MMR IgG antibodies was carried out by means of the commercial enzyme-linked immunosorbent assay (ELISA) Enzygnost (Dade Behring, Marburg, Germany). Antibody levels of $\mathrm{Ru}$ and Me were reported as positive (higher than 10 or $350 \mathrm{IU} / \mathrm{L}$, respectively), negative (lower than 5 or $150 \mathrm{IU} / \mathrm{L}$, respectively) or equivocal (5-10 or 150-350 IU/L, respectively). $\mathrm{Mu}$ antibody measurement was quantitative. According to the Center for Disease Control and Prevention (CDC) recommendations [5], equivocal results were processed as negative. 


\subsection{Statistics}

A 2 by 2 chi-squared $\left(\chi^{2}\right)$ test (Yates correction) was the statistical method used to compare the seroprevalence of antibodies. Other statistical analyses were descriptive. Further, multiple linear regression was used to analyse the variables influencing antibody behaviour, and the following outcomes were considered for the purpose of multiple linear regression if appropriate (independent variables): (1) the age at first dose of vaccine, (2) the date of the first dose of vaccine, (3) the date of birth, and (4) the interval since the dose (or the last dose) of vaccine; antibody titre (see below) was the dependent variable. For better interpretation of the results, antibody titres were categorized as 1 if negative, 2 if equivocal, and 3 if positive. Significance was defined by $p<0.05$. Statsdirect version 2.7 .7 (Statsdirect Ltd., UK) was used for statistical analyses.

\section{Results}

A high percentage of students born before 1980 (Figure 1, panel A) were not vaccinated against Ru, $\mathrm{Mu}$ or $\mathrm{Me}(74.1 \%, 97.4 \%$, and $87.7 \%$, respectively). Among those not vaccinated against Ru, females showed better compliance ("only" 56.5\% not vaccinated) than males (95.5\% not vaccinated). This is because vaccination against $\mathrm{Ru}$ was actively offered during female adolescence at the end of primary school or at the beginning of secondary school from 1972 to 1988-1989.
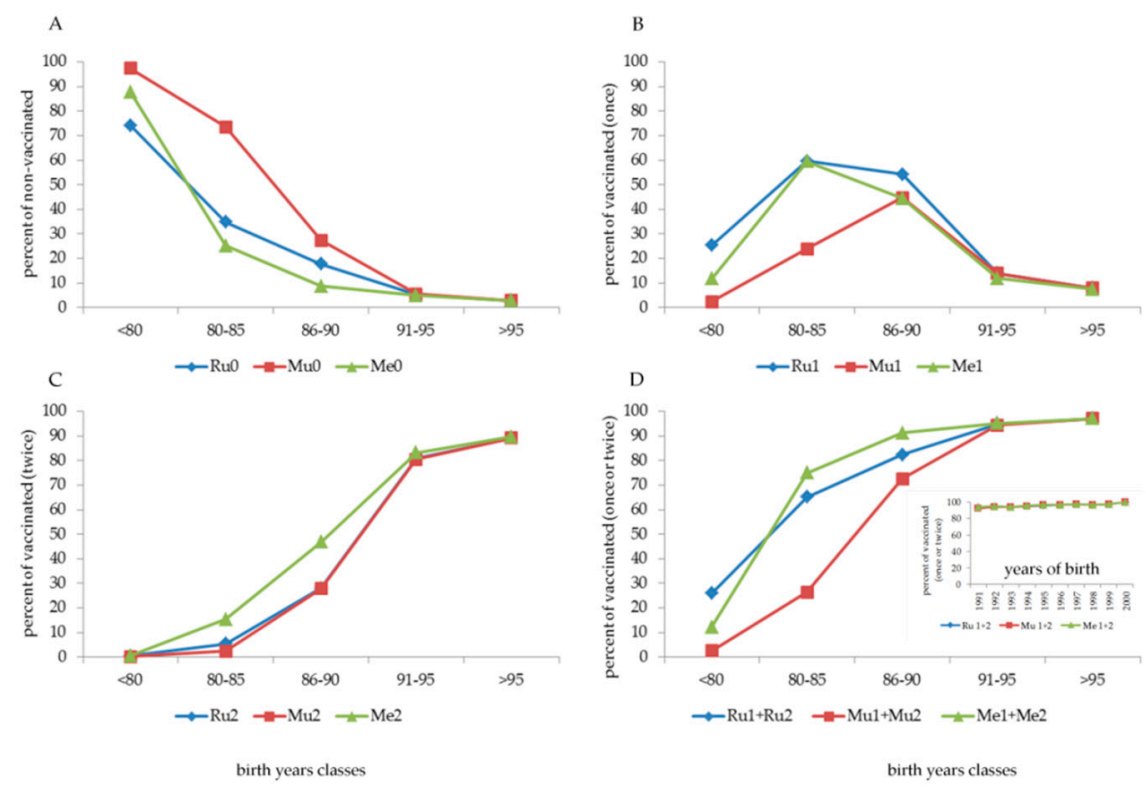

Figure 1. Percentage of subjects not vaccinated (panel A) or vaccinated with one (panel B), two (panel C) or one+two (panel D) doses according to date of birth classes. In the box at the bottom of panel D, the percentage of vaccinated subjects born between 1991 and 2000 with one+two doses is presented.

Furthermore (data not shown), among the subdivisions of the date of birth, in those born before 1960 (13 subjects), between 1960 and 1969 (73 subjects), and between 1970 and 1979 (409 subjects), the percentage of individuals not vaccinated against exanthematic diseases was 100\% in the first group; $94.5 \%(\mathrm{Ru}), 98.6 \%(\mathrm{Mu})$ and $97.3 \%(\mathrm{Me})$ in the second group; and $69.7 \%(\mathrm{Ru}), 97.1 \%(\mathrm{Mu})$ and $85.6 \%(\mathrm{Me})$ in the third group. Despite non-vaccination, the cohort born before 1980 showed a high percentage (higher than $90 \%$, except Mu, 77\%) of positive antibodies (Figure 2, panel A). 

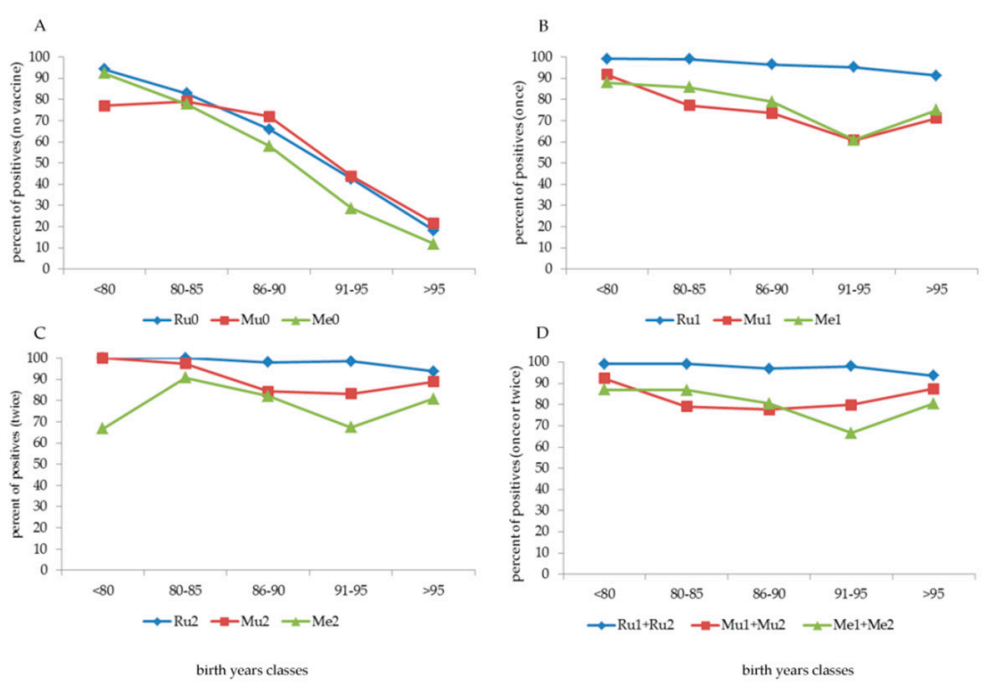

Figure 2. Percentage of positive antibodies against $\mathrm{Ru}, \mathrm{Mu}$ and $\mathrm{Ru}$ in subjects who were not vaccinated (panel A) and those who were vaccinated with one (panel B), two (panel C) or one+two (panel D) doses according to date of birth classes.

With an increasing date of birth, the number of non-vaccinated subjects decreased progressively to $5.2 \%$ if the students were born after 1990 and to $2.9 \%$ if born after 1995 (Figure 1, panel A). Among subjects born between 1980 and 1990, the number of vaccinated subjects increased, with one dose (cohort 1980-1985) and two doses (cohort 1985-1990) (Figure 1, panels B and C, respectively). Overall (Figure 1, panel D), more than 90\% of the cohorts born after 1990 had at least one dose of MMR vaccine, and most had two doses; if they were born after 1995, the vaccination coverage exceeded $95 \%$ (at least one dose) and reached $90 \%$ with two doses.

From what was reported in vaccination certificates, several combinations of $\mathrm{Ru}, \mathrm{Mu}$, or Me vaccines were administered (Table 1). Children born before 1980 and during the eighties were prevalently vaccinated (when vaccinated) with a single dose of $\mathrm{Ru}, \mathrm{Mu}$, or Me alone; the implementation of the MMR formulation (one dose only) started in the eighties, with a peak in 1986, and decreased throughout the years. A consistent cohort of children born after 1989 began to be vaccinated with two MMR doses (54.8\% of subjects), with a progressive increase during the nineties, with almost $95 \%$ coverage in children born in 1998 (Figure 1, panel A-D). As indicated in the box at the bottom of panel D of Figure 1, vaccination coverage with at least one dose, starting from those born in 1991, was greater than $94 \%$ and reached $97.8 \%-100 \%$ in those born in 1999 and 2000 .

Before the implementation and the achievement of high compliance with the MMR vaccine, the behaviour of parents regarding childhood vaccinations was different. Ru vaccination (Figure 1, panel C) was highly administered in more than $70 \%$ of females (commonly one dose). Generally, compliance with the Mu vaccine alone was low (Figure 1, panel B), at least until the implementation of the MMR formulation. In contrast, compliance with the Me vaccine (Figure 1, panel B-D), usually with one dose of Me alone, was sufficiently high (more than $50 \%$ ) by the beginning of the eighties.

The positivity of antibodies to $\mathrm{Ru}, \mathrm{Mu}$, and $\mathrm{Me}$ was high in older non-vaccinated students, but this rapidly decreased with an increasing date of birth (Figure 2, panel A). On the other hand, after vaccination, a different behaviour was observed on the basis of the number of doses and the vaccination type (Figure 2, panel B-D). One or two doses of the Ru vaccine induced a high antibody response of over $90 \%$.

An "anomaly" immediately catches the eye, i.e., the positive response to vaccination against $\mathrm{Mu}$ ( 1 dose) and Me (1 and 2 doses) in the age group born between 1991 and 1995, with the number of positive subjects being significantly lower $(p<0.0001)$ than that in the other age classes. To understand this "anomaly", the year of birth (Figure 3, panel A,B) and the year of the first vaccine dose for $\mathrm{Mu}$ and Me (Figure 3, panel C-D) were analysed separately, also analysing the three years before 1991 and the two years after 1995. The "indicted" years are 1991-1994 (Me one dose), 1991-1993 (Me two 
doses) and 1992-1995 (Mu one dose) according to the date of birth and 1993-1995 (all types of vaccine) according to the date of the first dose of vaccine. The second dose of vaccine against $\mathrm{Mu}$, but only partially against Me (independently by the years of vaccination), largely increased the percentage of positive subjects. A multivariate analysis (data not shown) applied to this cohort confirmed that the date of birth and the date at the first dose of vaccine significantly $(p<0.0001)$ influenced antibody titre after 1 dose of $\mathrm{Mu}$ vaccine and 1 or 2 doses of Me vaccine, but not after 2 doses of Mu vaccine.

Table 1. Type of vaccination against $\mathrm{Ru}, \mathrm{Mu}$ and $\mathrm{Me}$ (percentage in parentheses).

\begin{tabular}{cccccccc}
\hline Date of Birth & $\mathbf{N}$ & $\mathbf{R u 0}$ & $\mathbf{R u 1}$ & $\mathbf{M M R 1}$ & $\mathbf{R u + R u}$ & $\mathbf{R u + M M R}$ & MMR2 \\
\hline before 1980 & 495 & $367(74.1)$ & $115(23.2)$ & $10(2.0)$ & 0 & $2(0.4)$ & $1(0.2)$ \\
$1980-1985$ & 1544 & $538(34.8)$ & $626(40.5)$ & $295(19.1)$ & $3(0.2)$ & $51(3.3)$ & $31(2.0)$ \\
1986-1990 & 2685 & $474(17.7)$ & $285(10.6)$ & $1171(43.6)$ & 0 & $29(1.1)$ & $726(27.0)$ \\
1991-1995 & 3892 & $201(5.2)$ & $15(0.4)$ & $522(13.4)$ & 0 & $24(0.6)$ & $3126(80.3)$ \\
after 1995 & 2037 & $60(2.9)$ & $1(0.05)$ & $160(7.9)$ & 0 & $2(0.1)$ & $1814(89.1)$ \\
\hline Date of Birth & $\mathbf{N}$. & $\mathbf{M u 0}$ & $\mathbf{M u 1}$ & $\mathbf{M M R 1}$ & $\mathbf{M u + M u}$ & $\mathbf{M u + M M R}$ & MMR2 \\
\hline before 1980 & 495 & $482(97.4)$ & 0 & $12(2.4)$ & 0 & 0 & $1(0.2)$ \\
1980-1985 & 1544 & $1137(73.6)$ & $30(1.9)$ & $339(22.0)$ & 0 & $7(0.5)$ & $31(2.0)$ \\
1986-1990 & 2685 & $736(27.4)$ & $23(0.9)$ & $1180(43.9)$ & 0 & $20(0.7)$ & $726(27.0)$ \\
1991-1995 & 3892 & $219(5.6)$ & $1(0.03)$ & $543(14.0)$ & 0 & $3(0.08)$ & $3126(80.3)$ \\
after 1995 & 2037 & $60(2.9)$ & $1(0.05)$ & $162(8.0)$ & 0 & 0 & $1814(89.1)$ \\
\hline Date of Birth & $\mathbf{N}$. & $\mathbf{M e 0}$ & $\mathbf{M e 1}$ & $\mathbf{M M R 1}$ & $\mathbf{M e + M e}$ & $\mathbf{M e + M M R}$ & MMR2 \\
\hline before 1980 & 495 & $434(87.7)$ & $48(9.7)$ & $10(2.0)$ & 0 & $2(0.4)$ & $1(0.2)$ \\
1980-1985 & 1544 & $388(25.1)$ & $760(49.2)$ & $156(10.1)$ & $19(1.2)$ & $188(12.2)$ & $33(2.1)$ \\
1986-1990 & 2685 & $234(8.7)$ & $505(18.8)$ & $690(25.7)$ & $20(0.7)$ & $510(19.0)$ & $726(27.0)$ \\
1991-1995 & 3892 & $189(4.9)$ & $30(0.8)$ & $435(11.2)$ & $1(0.03)$ & $111(20.9)$ & $3126(80.3)$ \\
after 1995 & 2037 & $59(2.9)$ & $2(0.1)$ & $150(7.4)$ & 0 & $13(0.6)$ & $1814(89.1)$ \\
\hline
\end{tabular}

Legend: $\mathrm{Ru} / \mathrm{Mu} / \mathrm{Me} 0=$ not vaccinated; $\mathrm{Ru} / \mathrm{Mu} / \mathrm{Me} 1$ or $\mathrm{Ru}+\mathrm{Ru} ; \mathrm{Mu}+\mathrm{Mu} ; \mathrm{Me}+\mathrm{Me}=$ vaccinated with specific vaccine alone; $\mathrm{MMR} 1$ = vaccinated once with trivalent vaccine; $\mathrm{Ru} / \mathrm{Mu} / \mathrm{Me}+\mathrm{MMR}=$ vaccinated with specific vaccine alone and MMR; MMR2 = vaccinated twice with trivalent vaccine.
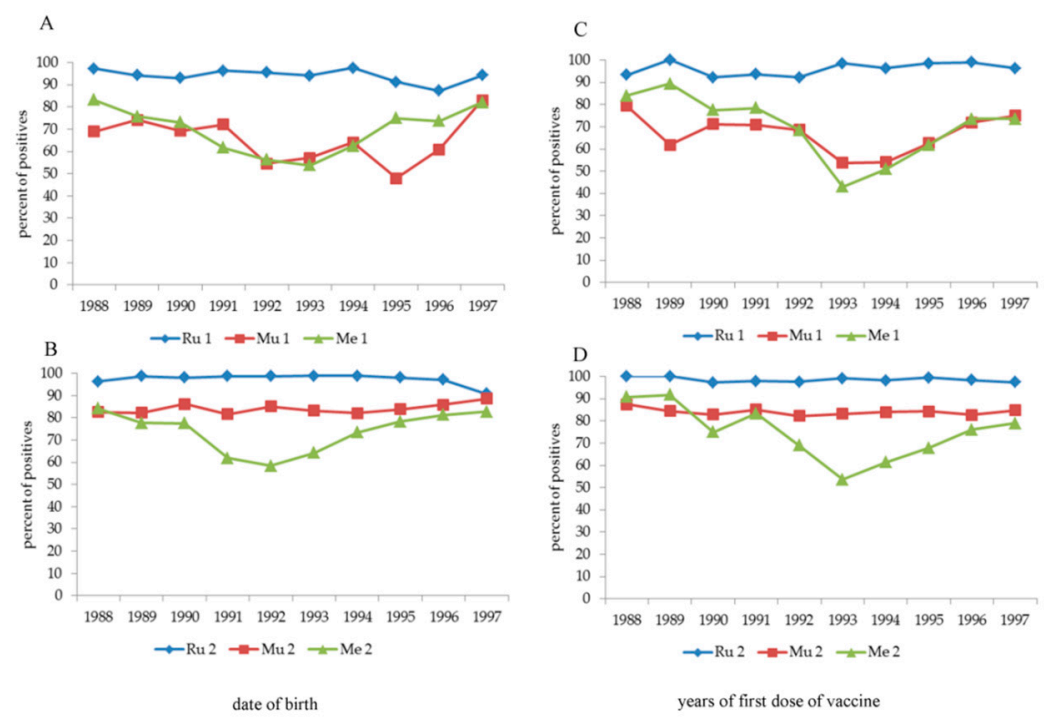

Figure 3. Percentage of positive antibodies against $\mathrm{Ru}, \mathrm{Mu}$ and $\mathrm{Ru}$ after one or two doses of vaccine according years of the date of birth (panel $\mathbf{A}, \mathbf{B}$ ) and the 1st dose of vaccine (panel C,D) in students born between 1988 and 1997.

In the whole population, the multivariate analysis (Tables 2 and 3) showed that date of birth influenced antibody titre only if subjects were vaccinated once $(\mathrm{Ru}, \mathrm{Mu}$, and $\mathrm{Me})$, whereas the date of vaccine or the 1st dose of vaccine influenced $\mathrm{Ru}$ (once) or Me (twice) and the interval since the vaccine (or 2nd dose) influenced $\mathrm{Ru}$ and Me (once and twice), but not $\mathrm{Mu}$. 
Table 2. Multiple linear regression among antibodies ( $\mathrm{Ab}$ ) of $\mathrm{Ru}, \mathrm{Mu}$ and $\mathrm{Me}$ after one dose and the independent variables date of birth, date of vaccine, and interval between vaccination and antibody measurement. Significant results are shown in bold.

\begin{tabular}{ccccc}
\hline Ru & $\mathbf{b}$ & $\mathbf{r}$ & $\mathbf{t}$ & $\mathrm{p}$ \\
\hline intercept & 3.25218 & & 22.77316 & $<0.0001$ \\
date of birth & $-\mathbf{0 . 0 0 0 0 2 1}$ & -0.093403 & -5.306036 & $<0.0001$ \\
date of vaccine & $\mathbf{0 . 0 0 0 0 1 2}$ & $\mathbf{0 . 0 3 9 6 1 9}$ & $\mathbf{2 . 2 4 2 6 2 3}$ & $=0.025$ \\
interval & -0.00001 & -0.038574 & -2.183368 & $=0.0291$ \\
\hline
\end{tabular}

$\mathrm{Ru} \mathrm{Ab}$ one dose $=3.25218-0.000021$ date of birth +0.000012 date of vaccine -0.00001 interval

\begin{tabular}{ccccc}
\hline $\mathbf{M u}$ & $\mathbf{b}$ & $\mathbf{r}$ & $\mathbf{t}$ & $\mathbf{p}$ \\
\hline intercept & 4.330541 & & 7.786166 & $<0.0001$ \\
date of birth & $\mathbf{- 0 . 0 0 0 0 8}$ & $\mathbf{- 0 . 0 8 8 6 7 9}$ & $\mathbf{- 4 . 2 5 7 6 4 8}$ & $<\mathbf{0 . 0 0 0 1}$ \\
date of vaccine & 0.000026 & 0.024039 & 1.149929 & $=0.2503$ \\
interval & -0.000016 & -0.015281 & -0.730871 & $=0.4649$ \\
\hline
\end{tabular}

$\mathrm{Mu} \mathrm{Ab}$ one dose $=4.330541-0.00008$ date of birth +0.000026 date of vaccine -0.000016 interval.

\begin{tabular}{ccccc}
\hline Me & $\mathbf{b}$ & $\mathbf{r}$ & $\mathbf{t}$ & $\mathbf{p}$ \\
\hline intercept & 5.806215 & & 15.709522 & $<0.0001$ \\
date of birth & $-\mathbf{0 . 0 0 0 0 5 8}$ & $-\mathbf{0 . 0 8 3 5 6 7}$ & $-\mathbf{4 . 4 2 4 7 5 7}$ & $<0.0001$ \\
date of vaccine & -0.000027 & -0.032669 & -1.724637 & $=0.0847$ \\
interval & $-\mathbf{0 . 0 0 0 0 5 4}$ & $-\mathbf{0 . 0 7 0 9 4 4}$ & $-\mathbf{3 . 7 5 2 7 2}$ & $=\mathbf{0 . 0 0 0 2}$ \\
\hline
\end{tabular}

$\mathrm{Me} \mathrm{Ab}$ one dose $=5.806215-0.000058$ date of birth -0.000027 date of vaccine -0.000054 interval.

Table 3. Multiple linear regression among antibodies ( $\mathrm{Ab}$ ) of $\mathrm{Ru}, \mathrm{Mu}$ and $\mathrm{Me}$ after two doses and the independent variables date of birth, date of vaccine, and interval since the last dose and antibody measurement. Significant results are shown in bold.

\begin{tabular}{ccccc}
\hline Ru & $\mathbf{b}$ & $\mathbf{r}$ & $\mathbf{t}$ & $\mathbf{p}$ \\
\hline intercept & 3.493779 & & 25.100325 & $<0.0001$ \\
date of birth & -0.000006 & -0.0122 & -0.929521 & $=0.3527$ \\
date of 1st dose & $+6.60 \mathrm{E}-07$ & 0.002247 & 0.171188 & $=0.8641$ \\
date of 2nd dose & -0.000007 & -0.012479 & -0.95077 & $=0.3418$ \\
interval since the & $\mathbf{- 0 . 0 0 0 0 2 3}$ & $\mathbf{- 0 . 0 4 8 2 4 9}$ & $\mathbf{- 3 . 6 8 0 1 0 9}$ & $\mathbf{0 . 0 0 0 2}$ \\
last dose & & &
\end{tabular}

$\mathrm{Ru} \mathrm{Ab}$ two doses $=3.493779-0.000006$ date of birth $+6.60 \mathrm{E}-07$ date 1 st dose -0.000007 date 2 nd dose -0.000023 interval since the last dose.

\begin{tabular}{ccccc}
\hline $\mathbf{M u}$ & $\mathbf{b}$ & $\mathbf{r}$ & $\mathbf{t}$ & $\mathbf{p}$ \\
\hline intercept & 1.432912 & & 3.692206 & $=0.0002$ \\
date of birth & -0.000018 & -0.012968 & -0.981099 & $=0.3266$ \\
date of 1st dose & -0.000009 & -0.010251 & -0.77555 & $=0.438$ \\
date of 2nd dose & $\mathbf{0 . 0 0 0 0 5 7}$ & $\mathbf{0 . 0 3 7 7 7 3}$ & $\mathbf{2 . 8 5 9 5 9 9}$ & $=\mathbf{0 . 0 0 4 3}$ \\
interval since the & 0.000029 & 0.022088 & 1.67139 & $=0.0947$ \\
last dose & & & &
\end{tabular}

$\mathrm{Mu} \mathrm{Ab}$ two doses $=1.432912-0.000018$ date of birth -0.000009 date 1 st dose +0.000057 date 2 nd dose +0.000029 interval since the last dose.

\begin{tabular}{ccccc}
\hline $\mathbf{M e}$ & $\mathbf{b}$ & $\mathbf{r}$ & $\mathbf{t}$ & $\mathbf{p}$ \\
\hline intercept & 4.801932 & & 13.227424 & $<0.0001$ \\
date of birth & -0.000002 & -0.001449 & -0.117342 & $=0.9066$ \\
date of 1st dose & $\mathbf{0 . 0 0 0 0 9 2}$ & $\mathbf{0 . 0 8 3 7 0 3}$ & $\mathbf{6 . 8 0 1 2 4}$ & $<0.0001$ \\
date of 2nd dose & $-\mathbf{0 . 0 0 0 1 3 3}$ & $\mathbf{- 0 . 0 8 0 6 1}$ & -6.54827 & $<0.0001$ \\
interval since the & $\mathbf{- 0 . 0 0 0 0 6 7}$ & $\mathbf{- 0 . 0 4 7 6 0 4}$ & $\mathbf{- 3 . 8 5 8 8 6 6}$ & $=\mathbf{0 . 0 0 0 1}$ \\
last dose & & &
\end{tabular}

$\overline{\mathrm{Me}} \mathrm{Ab}$ two doses $=4.801932-0.000002$ date of birth +0.000092 date 1 st dose -0.000133 date 2 nd dose -0.000067 interval since the last dose. 
$\mathrm{Me} \mathrm{Ab}$ one dose $=5.806215-0.000058$ date of birth -0.000027 date of vaccine -0.000054 interval.

Tables 4 and 5 show the average ages to which the only dose of vaccine (vaccinated once) or the first and second dose (vaccinated twice) were administered, respectively.

Table 4. Age of vaccination of students vaccinated once.

\begin{tabular}{cccccc}
\hline Date of Birth & Vaccine Type & N. & Mean \pm SD & Median & Range \\
\hline before 1980 & Ru1 & 125 & $11.6 \pm 5.0$ & 10.9 & $<1-37$ \\
& Mu1 & 12 & $21.6 \pm 11.9$ & 23.0 & $<1-37$ \\
\multirow{3}{*}{$1980-1985$} & Me1 & 58 & $8.7 \pm 8.7$ & 5.5 & $1-37$ \\
& Ru1 & 921 & $10.6 \pm 2.7$ & 10.9 & $<1-26$ \\
& Mu1 & 369 & $10.2 \pm 4.8$ & 11.0 & $<1-24$ \\
$1986-1990$ & Me1 & 918 & $4.0 \pm 4.3$ & 2.0 & $<1-25$ \\
& Ru1 & 1456 & $8.1 \pm 4.7$ & 11.0 & $<1-24$ \\
& Mu1 & 1203 & $7.4 \pm 4.9$ & 10.5 & $<1-24$ \\
$1991-1995$ & Me1 & 1195 & $3.6 \pm 3.6$ & 1.8 & $<1-24$ \\
& Ru1 & 540 & $6.1 \pm 5.4$ & 2.4 & $<1-21$ \\
& Mu1 & 544 & $6.0 \pm 5.4$ & 2.3 & $<1-21$ \\
after 1995 & Me1 & 465 & $4.4 \pm 4.7$ & 1.7 & $<1-21$ \\
& Ru1 & 161 & $3.7 \pm 4.3$ & 1.5 & $1-20$ \\
& Mu1 & 163 & $3.6 \pm 4.2$ & 1.5 & $1-20$ \\
& Me1 & 152 & $3.2 \pm 4.0$ & 1.5 & $1-20$ \\
\hline
\end{tabular}

Table 5. Age of vaccination of students vaccinated twice.

\begin{tabular}{|c|c|c|c|c|c|c|c|c|}
\hline Date of Birth & Vaccine Type & N. & \multicolumn{3}{|c|}{ Age at 1st Dose } & \multicolumn{3}{|c|}{ Age at 2nd Dose } \\
\hline \multirow[t]{2}{*}{ 1980-1985 } & $\mathrm{Ru} 2$ & 85 & $6.4 \pm 4.7$ & 7.2 & $<1-21$ & $14.0 \pm 4.5$ & 11.9 & $10-27$ \\
\hline & $\mathrm{Me} 2$ & 238 & $2.6 \pm 2.1$ & 1.7 & $<1-21$ & $11.9 \pm 3.1$ & 11.4 & $<1-21$ \\
\hline 1986-1990 & $\mathrm{Ru} 2$ & 755 & $2.3 \pm 2.3$ & 1.5 & $1-17$ & $12.3 \pm 2.3$ & 11.6 & $1-24$ \\
\hline \multirow[t]{3}{*}{ 1991-1995 } & $\mathrm{Ru} 2$ & 3150 & $2.1 \pm 1.9$ & 1.5 & $<1-19$ & $11.7 \pm 2.0$ & 11.7 & $<1-23$ \\
\hline & $\mathrm{Mu} 2$ & 3129 & $2.0 \pm 1.8$ & 1.5 & $<1-19$ & $11.7 \pm 2.0$ & 11.7 & $<1-23$ \\
\hline & $\mathrm{Me} 2$ & 3238 & $2.0 \pm 1.8$ & 1.5 & $<1-19$ & $11.7 \pm 2.0$ & 11.7 & $<1-23$ \\
\hline \multirow[t]{2}{*}{ after 1995} & $\mathrm{Ru} 2$ & 1816 & $1.7 \pm 1.5$ & 1.4 & $<1-19$ & $8.2 \pm 2.6$ & 7.7 & $1-20$ \\
\hline & $\mathrm{Mu} 2$ & 1814 & $1.7 \pm 1.5$ & 1.4 & $<1-19$ & $8.2 \pm 2.6$ & 7.7 & $1-20$ \\
\hline
\end{tabular}

Note: Age classes born before 1980 were excluded because they were too limited in number.

\section{Discussion}

The aim of this research was based on two issues: (1) vaccination and (2) immune coverage. Vaccination and immune coverage do not always go together, and the reason for this discrepancy can be attributed primarily to five causes: (1) the type of vaccine used, (2) the interval since the last dose, (3) age [6], (4) sex differences [7], and (5) racial differences [8,9].

The analysis of data on vaccination and immune coverage in a cohort of medical students shows that date of birth and the date of the first dose of vaccine widely influence immune response. In addition, there are two further lines of evidence, namely, (1) the progressive awareness of parents about the need to vaccinate their children against $\mathrm{Me}, \mathrm{Mu}$, and $\mathrm{Ru}$ and (2) probable differences in the formulation of vaccines.

According to the second hypothesis, certainly the most striking is the introduction of the Rubini strain against $\mathrm{Mu}$ in 1991 in the TRIVIRATEN ${ }^{\circledR}$ formulation, which was proven to be ineffective and was subsequently withdrawn from the market. A comparative study between the different strains in use against $\mathrm{Mu}$, i.e., Jeryl-Lynn, Urabe, and Rubini, showed that the efficacy was 80.7\%, 54.4\% and 
$-55.3 \%$, respectively [10]. This may explain the response to vaccination in the 1991-1995 cohort, which was significantly lower after one MMR dose. On the other hand, the same cohort vaccinated twice reached an immune coverage of $80 \%$ or more; two doses of vaccine were already necessary to maintain immune coverage.

In the same cohort, the significant decrease in immune coverage after vaccination against $\mathrm{Me}$ appears less explainable, showing a similar trend to that of $\mathrm{Mu}$, but not corrected by the second dose. MORUPAR ${ }^{\circledR}$ (Schwartz strain) was also introduced in those years and was then withdrawn in early 2000, but not because of the ineffectiveness of the strain but because of problems concerning a higher incidence of serious allergic reactions. Currently, we have no convincing explanations for this phenomenon except a possible "negative" influence of the Rubini strain on the Edmonton-Zagreb strain used for $\mathrm{Me}$, but it remains inexplicable why the second dose, as in the case of $\mathrm{Mu}$, did not remedy the failure of the first. Unfortunately, the type of vaccine used is not information that is provided in vaccination certificates. In addition, in a comparison of this phenomenon between years of first dose of vaccine and the date of birth, the loss in immune coverage is delayed by 1-1.5 years with respect to the date of birth because vaccination is usually administered after the first year of age. There appears to be some hesitancy in children vaccinated with a single dose, even for those born in more recent years. This hesitancy could explain the non-completion of the vaccination cycle.

The necessity of vaccination implementation is related to the decline in subjects naturally immunized over time. It is known that the circulation of $\mathrm{Ru}, \mathrm{Mu}$ and, above all, $\mathrm{Me}$ is dramatically decreased compared to 40 years ago [11], but Me virus after infection may cause subacute sclerosing panencephalitis [12,13] or, when infecting immune cells, acute immune suppression with a reduction in humoral immune system and a low response to future infectious diseases [14,15]. These effects are not observed after vaccination.

A relevant question is that, despite good vaccination coverage, the immune coverage for $\mathrm{Mu}$ and Me is, on average and minus the problems concerning the 1991-1995 cohort, lower than $90 \%$; on the contrary, immune coverage for $\mathrm{Ru}$ is higher than $95 \%$, even after only one dose of vaccine. For this reason, for $\mathrm{Mu}$ and $\mathrm{Me}$ herd immunity, which are over $90 \%$ and over $95 \%$, respectively, is apparently not achieved. Regardless, only vaccination coverage higher than $95 \%$ permits good herd immunity for Me [16], and for optimal herd immunity, everyone should be vaccinated [17].

In the most recent position paper on $\mathrm{Me}$, the WHO [18] concluded that "although vaccine-induced antibody concentrations decline over time and may become undetectable, immunological memory persists and, following exposure to measles virus, most people who have been vaccinated produce a protective immune response". Nevertheless, Me cases may also occur in twice-vaccinated subjects $[19,20]$. Waning antibodies and differences in virus genotype of the vaccine and of circulating strain may be a possible explanation [21]; in contrast, older studies stated that cellular immunity induced by the Me vaccine probably protects vaccinated subjects [22] despite trace amounts of circulating antibodies [23]. Further, waning immunity may occur due to a lack of boosting from circulating wild-type virus [24]. Moreover, the waning of both the concentration and the avidity of antibodies might contribute to Me infection in twice-MMR-vaccinated subjects [25].

The position of $\mathrm{WHO}$ on measles is clear and does not propose booster doses over time after the two-dose cycle. This is justifiable in the general population, but what about for HCWs? The issue, at least in Italy, is debated. Quite recently [26], in subjects vaccinated with two doses during childhood, one booster dose guaranteed a seroconversion of $74 \%$ and a second of $93 \%$, without significant adverse effects. However, is it ethically acceptable to suggest a booster dose not deemed necessary by international authorities? Nevertheless, a third dose of vaccine is also suggested in twice-vaccinated subjects, in particular in HCWs [27]. The outbreak of Me in Italy in 2017 caused 5407 cases of illness, 4 of which were followed by death. The vast majority of cases of disease occurred in unvaccinated patients, but $7.2 \%$ were vaccinated once and 1.6\% twice; the low vaccination coverage of HCWs was also the cause of 334 illnesses among these individuals [28]. 
The present research has two weaknesses: (1) without knowing the type of vaccine (especially for the MMR vaccine) used, the evaluation of the 1991-1995 cohort is speculative; and (2) the antibody measurement was done with an EIA method, but the measurement of neutralizing antibodies might be better correlated with protection $[29,30]$. On the other hand, the strengths of the study lie in the size of the sample, the use of vaccination certificates (although they lack the information noted above), and the completeness of the health documentation.

\section{Conclusions}

In conclusion, the question posed in the title can be answered affirmative; we will have a new generation of HCWs covered by MMR vaccination. The $95 \%$ herd immunity for Me will probably be overcome, and a more complex evaluation regarding the immune coverage, which is optimal for $\mathrm{Ru}$ (probably a single dose would be enough) but not for $\mathrm{Mu}$ and $\mathrm{Me}$, will be achieved. What worries us most is Me, given the possible immediate and delayed complications as a consequence of viral infection. On the other hand, accordingly to the WHO [18] a full cycle of MMR in infancy should be enough to ensure adequate coverage even in the event of the disappearance of circulating antibodies. Finally, an open problem is if and when a subject must be declared a non-responder.

Author Contributions: Conceptualization, A.T., C.B., and S.M; methodology, A.T., A.N.; validation, A.T., C.B., S.M. and A.N.; formal analysis, A.T.; data curation, L.L., E.A., C.F., D.D.N.; writing-original draft preparation, A.T.; writing-review and editing, A.N., D.D.N, S.M.; supervision, A.T.; All authors have read and agreed to the published version of the manuscript.

Funding: This research received no external funding

Conflicts of Interest: The authors declare no conflict of interest.

\section{References}

1. Attwell, K.; Navin, M.C.; Lopalco, P.L.; Jestin, C.; Reiter, S.; Omer, S.B. Recent vaccine mandates in the United States, Europe and Australia: A comparative study. Vaccine 2018, 36, 7377-7384. [CrossRef] [PubMed]

2. Davidkin, I.; Jokinen, S.; Broman, M.; Leinikki, P.; Peltola, H. Persistence of measles, mumps, and rubella antibodies in an MMR-vaccinated cohort: A 20-years follow-up. J. Infect. Dis. 2008, 197, 950-956. [CrossRef] [PubMed]

3. Watson, J.C.; Pearson, J.A.; Markowitz, L.E.; Baughman, A.L.; Erdman, D.D.; Bellini, W.J.; Baron, R.C.; Fleming, D.W. Evaluation of measles revaccination among schoolentry-aged children. Pediatrics 1996, 97, 613-618. [PubMed]

4. Trevisan, A.; Morandin, M.; Frasson, C.; Paruzzolo, P.; Davanzo, E.; Di Marco, L.; Fabrello, A.; Borella-Venturini, M. Prevalence of childhood exanthematic disease antibodies in paramedical students: Need of vaccination. Vaccine 2006, 24, 171-176. [CrossRef] [PubMed]

5. Centers for Disease Control and Prevention. Prevention of varicella. Update recommendations of the Advisory Committee on Immunization Practices (ACIP). Morb. Mortal. Wkly. Rep. 1999, 48, (No RR-6). 1-5.

6. Panda, A.; Qian, F.; Mohanty, S.; van Duin, D.; Newman, F.K.; Zhang, L.; Chen, S.; Towle, V.; Belshe, R.B.; Fikrig, E.; et al. Age-associated decrease in TLR function in primary human dendritic cells predicts influenza vaccine response. J. Immunol. 2010, 184, 2518-2527. [CrossRef] [PubMed]

7. Klein, S.L.; Jedlicka, A.; Pekosz, A. The Xs and Y of immune responses to viral vaccines. Lancet Infect. Dis. 2010, 10, 338-349. [CrossRef]

8. Haralambieva, I.H.; Salk, H.M.; Lambert, N.D.; Ovsyannikova, I.G.; Kennedy, R.B.; Warner, N.D.; Pankratz, V.S.; Poland, G.A. Associations between race, sex and immune response variations to rubella vaccination in two independent cohorts. Vaccine 2014, 32, 1946-1953. [CrossRef]

9. Happe, M.; Samuvel, D.J.; Ohtola, J.A.; Korte, J.E.; Westerink, M.A.J. Race-related differences in functional antibody response to pneumococcal vaccination in HIV-infected individuals. Vaccine 2019, 37, 1622-1629. [CrossRef]

10. Ong, G.; Goh, K.T.; Ma, S.; Chew, S.K. Comparative efficacy of Rubini, Jeryl-Lynn and Urabe mumps vaccine in an Asian population. J. Infect. 2005, 51, 294-298. [CrossRef]

11. World Health Organization. Global and Regional Immunization Profile; WHO: Geneva, Switzerland, 2018. 
12. Wendorf, K.A.; Winter, K.; Zipprich, J.; Schechter, R.; Hacker, J.K.; Preas, C.; Cherry, J.D.; Glaser, C.; Harriman, K. Subacute Sclerosing Panencephalitis: The Devastating Measles Complication That Might Be More Common Than Previously Estimated. Clin. Infect. Dis. 2017, 65, 226-232. [CrossRef] [PubMed]

13. Garg, R.K.; Mahadevan, A.; Malhotra, H.S.; Rizvi, I.; Kumar, N.; Uniyal, R. Subacute sclerosing panencephalitis. Rev. Med. Virol. 2019, 29, e2058. [CrossRef] [PubMed]

14. Mina, M.J.; Kula, T.; Leng, Y.; Li, M.; de Vries, R.D.; Knip, M.; Siljander, H.; Rewers, M.; Choy, D.F.; Wilson, M.S.; et al. Measles virus infection diminishes preexisting antibodies that offer protection from other pathogens. Science 2019, 366, 599-606. [CrossRef] [PubMed]

15. Petrova, V.N.; Sawatsky, B.; Han, A.X.; Laksono, B.M.; Walz, L.; Parker, E.; Pieper, K.; Anderson, C.A.; de Vries, R.D.; Lanzavecchia, A.; et al. Incomplete genetic reconstitution of B cell pools contributes to prolonged immunosuppression after measles. Sci. Immunol. 2019, 4, eaay6125. [CrossRef] [PubMed]

16. Anderson, R.M.; May, R.M. Immunisation and herd immunity. Lancet 1990, 335, 641-645. [CrossRef]

17. Bester, J.C. Measles vaccination is best for children: The argument for relying on herd immunity fails. J. Bioeth. Inq. 2017, 14, 375-378. [CrossRef]

18. [No authors listed] Measles vaccines: WHO position paper-April 2017. Wkly. Epidemiol. Rec. 2017, 92, $205-227$.

19. Risco-Risco, C.; Masa-Calles, J.; López-Perea, N.; Echevarría, J.E.; Rodríguez-Caravaca, G. Epidemiology of measles in vaccinated people, Spain 2003-2014. Enferm. Infecc. Microbiol. Clin. 2017, 35, 569-573. [CrossRef]

20. Cherry, J.D.; Zahn, M. Clinical Characteristics of Measles in Previously Vaccinated and Unvaccinated Patients in California. Clin. Infect. Dis. 2018, 67, 1315-1319. [CrossRef]

21. Gidding, H.F.; Quinn, H.E.; Hueston, L.; Dwyer, D.E.; McIntyre, P.B. Declining measles antibodies in the era of elimination: Australia's experience. Vaccine 2018, 36, 507-513. [CrossRef]

22. Bellanti, J.A.; Sanga, R.L.; Klutinis, B.; Brandt, B.; Artenstein, M.S. Antibody responses in serum and nasal secretions of children immunized with inactivated and attenuated measles-virus vaccines. N. Engl. J. Med. 1969, 280, 628-633. [CrossRef] [PubMed]

23. Samb, B.; Aaby, P.; Whittle, H.C.; Seck, A.M.; Rahman, S.; Bennett, J.; Markowitz, L.; Simondon, F. Serologic status and measles attack rates among vaccinated and unvaccinated children in rural Senegal. Pediatr. Infect. Dis. J. 1995, 14, 203-209. [CrossRef] [PubMed]

24. Moss, W. Measles in Vaccinated Individuals and the Future of Measles Elimination. Clin. Infect. Dis. 2018, 67, 1320-1321. [CrossRef] [PubMed]

25. Kontio, M.; Jokinen, S.; Paunio, M.; Peltola, H.; Davidkin, I. Waning antibody levels and avidity: Implications for MMR vaccine-induced protection. J. Infect. Dis. 2012, 206, 1542-1548. [CrossRef] [PubMed]

26. Bianchi, F.P.; Stefanizzi, P.; de Nitto, S.; Larocca, A.M.V.; Germinario, C.; Tafuri, S. Long-term immunogenicity of Measles vaccine: An Italian retrospective cohort study. J. Infect. Dis. 2019, 221, 721-728. [CrossRef]

27. Plotkin, S.A. Is There a Correlate of Protection for Measles Vaccine? J. Infect. Dis. 2019, jiz381. [CrossRef]

28. Filia, A.; Bella, A.; Del Manso, M.; Rota, M.C. L'epidemia di morbillo in Italia nel 2017. Riv. Immunol. Allergol. Ped. 2018, 2, 10-14. (In Italian)

29. Haralambieva, I.H.; Kennedy, R.B.; Ovsyannikova, I.G.; Whitaker, J.A.; Poland, G.A. Variability in Humoral Immunity to Measles Vaccine: New Developments. Trends Mol. Med. 2015, 21, 789-801. [CrossRef]

30. Haralambieva, I.H.; Kennedy, R.B.; Ovsyannikova, I.G.; Schaid, D.J.; Poland, G.A. Current perspectives in assessing humoral immunity after measles vaccination. Expert Rev. Vaccines 2019, 18, 75-87. [CrossRef]

(C) 2020 by the authors. Licensee MDPI, Basel, Switzerland. This article is an open access article distributed under the terms and conditions of the Creative Commons Attribution (CC BY) license (http://creativecommons.org/licenses/by/4.0/). 